\title{
I went there with my guitar a case study in a highly parcelled mental healthcare Scenario
}

\section{Introduction}

In the last forty years, Italy has gone through an improvement in life expectancy of about ten years for both men and women, yet with a slow decrease of the general population growth. ${ }^{1}$ Does it mean that life and health conditions have improved at all? Food and healthcare are not the only things to consider. This period of surprising demographic and social changes overlaps the one of the so-called "Italian Psychiatric Reform”, which led finally to the closure of the last mental hospital in 2002, at least formally. ${ }^{2}$ In 2005, the World Health Organisation held a conference on mental health in Helsinki to set the standards for mental health assistance in Europe. Each participant nation and Italy as well endorsed the statement that "there is no health without mental health". Among its Sustainable Development Goals expected to be achieved by 2030, the WHO put three targets related to mental health: to promote mental health and wellbeing, to promote universal health coverage and to strengthen the prevention and treatment of substance abuse.

In this paper, we will present the current mental healthcare scenario in Italy, with particular attention at the contemporary situation in the North-eastern region of Veneto. Rethinking the idea of "mental health" has been the drive of the Democratic Psychiatry movement (Psichiatria Democratica) since the 1960s. Among others, the deep insights of psychiatrist Franco Basaglia stood out as far as today. Beyond the closure of asylums and the quitting of constraining measures, achieved by Basaglia, it is important to understand the contemporary situation, which of those revolutionary ideas and to what point have been enacted. After all, Jean-Paul Sartre, in regard of the work did by Basaglia, said "if you want to see a reality where a practical knowledge is developed, go to Gorizia", ${ }^{1}$ so we have chosen to observe a facility in Padua in order to make an initial comparison for future observations on the present "practical knowledge". Despite its complexity and multifaceted solutions - in regard of which we will attempt to give some insights - the Italian scenario still shows some chronicity, a sort of past heritage left from asylums and from what the psychiatrist and chief of Democratic Psychiatry calls "historical paradigm" of the Italian psychiatry (Pirelli 2008). We rely on various sources, mostly interviews in a context of participated assistance experience of mentally ill people bound to a daily-open facility in Padua $^{3}$ one of the major urban centre in Veneto with a high number of

${ }^{1}$ In 1976, the life span for men was 69 years, women 75 years; in 2016 was respectively 80 and 85 . About general population growth, the country trend slowed down in 1990s. In the last twenty years, the population growth was fostered by immigration that rapidly increased from early 2000. See ISTAT data: URL http://www.istat.it/it/files/2017/03/Statistica-report-Indicatoridemografici_2016.pdf

${ }^{2}$ It is not the case of judiciary mental hospital (Ospedale Psichiatrico Giudiziario, OPG), which not refers to Ministry of Health's regulations but to Ministry of Justice. The closure of OPG was planned for 31 March 2015 (see Corriere della Sera, 9 Marzo 2015. URL http://www.corriere.it/cronache/15 marzo_09/gli-ultimi-internati-nostra-storia-cosi-finisce-un-ideadetenzione857b4544-c623-11e4-80fc-ae05ebe65fb1.shtml

3The quotations following in the next sections are taken from a total of 4 hours of interviews carried out by Filippi between 2016-2017. The subjects interviewed are the musician leading the music laboratory, the psychologist in charge of the facility, one operator and one educator; all the interviews
Volume I Issue $6-2017$

\author{
Stefano Galeazzi,' Nicolò Filippi² \\ 'Lumière University of Lyon 2, France \\ ${ }^{2} \mathrm{Ca}$ ' Foscari University of Venice, Italy
}

Correspondence: Stefano Galeazzi, Lumière University of Lyon 2, France, Email stgaleazzi@gmail.com

Received: April 10, 2017| Published: September 12, 2017

accesses to mental health facilities. ${ }^{4}$

\section{The general scenario}

\section{Mental illness, anthropology and society}

"Why should socio-cultural anthropology study the mental health assistance service today?" is a vicious question to start with. Rather we prefer "what is keen to be observed by socio-cultural anthropology today in mental health system?" Yet, does make any sense talk about a "mental health system", is not it one and only with all healthcare services? According to Helsinki conference, it is supposed to be, but reality has some grades of variation from what is expected to be. As we said in the introduction, Italy has changed both socially and culturally since forty years ago and thus did the condition of mentally ill people. The revolutionary ideas of Democratic Psychiatry, led by Basaglia, wanted freedom of choice and full rights for patients as much as was for other citizens. They proposed a psychiatric assistance based on the community (located in towns, cities, etc) and the end of measurements meant to constrain patients. All that the concept of asylum which had lot in common with prisons negated to its patients. Although those ideas were partially realized, Democratic Psychiatry's members have criticized the fading attention paid by institutions about old as well as new priorities, which have arisen in the last years. ${ }^{5}$ A clear sign

have been recorded on digital format on permission. Furthermore, Filippi has asked informally to other professionals involved in mental healthcare some questions about internal organization, typology of treatment and patients life. Then, more enquires have been pursued among friends, relatives, neighbors of Authors, without any special criterion about the choice of the enquired person. Obviously, in order to focus further on the common perception of mental health and attitudes toward it an array of questionnaires need to be arranged in the future.

${ }^{4}$ In 2009, the most significative numbers of people accessing mental health facilities were found in Verona $(6,296)$ and Padua $(6,264)$. These amounts include the patients followed by territorial services as well as those followed by hospital services because the seriousness of their conditions. See p. 10 URL http:/www.ser-veneto.it/public/File/documents/rapporti/ RapportoSaluteMentale2010.pdf

${ }^{5}$ In occasion of Festival dei Matti (see below), the Authors have met Basaglia's ex-coworkers who expressed a growing dissatisfaction with the constraining measures still used in Italian psychiatric assistance. In this paper, we consider briefly the pharmacological therapy as a new kind of means to control physically the patients. For a broader range of professional and nonprofessional opinions about the current situation of mental healthcare in Italy, see also Lupo, di Fede (2008). 
is the underfunding of mental health departments in Veneto region and consequently a reduction in prevention, therapy and rehabilitation service. $^{6}$ This critique is shared overseas by Jessica Mackanzie ${ }^{2}$ who begins a brief article entitled Prioritising mental health, ${ }^{2}$ in which she points out that the "global mental health is desperately underfunded", which confirmed on the regional level by professionals in charge of Padua outpatient facilities, too. It is not about mental hospitals anymore, nowadays it concerns a large system of facilities and structures monitoring and acting within the Italian territory, from the inside of its society in order to assure the general health of population. As the latter changed a lot over time, it is necessary to ask how the relationship, the understanding, the positionality in relation to mental health issue - as disease to care of, but also as a wide open social matter dealt by formal and informal institutions (from medical to volunteering) - changed in comparison to 60s'. Certainly, we can state that the general population is experiencing a more close contact with mentally ill people and the general mental health issue, despite some kind of exoticism still visible on social networks, whereby the "psychiatry" word itself (often turned up in or associated with pictures) appears to be surrounded somewhat by fascination, thus banned from the normal speech topics, counted as experience of Otherness.

In the second half of the twenty-first century, thanks to a spread wellbeing of general population, Italy underwent a "second demographic transition" which turned out to be something as much unexpected by demographics as they labelled it the "grandparents' century"., In other words, the recent decades registered an over turning's trend of the demographical pyramid, ${ }^{8}$ that is to say the Italian family shape has changed from a horizontal one (more components, shorter life) to a vertical one (fewer components, longer life). This phenomenon, which has been called "verticalization of kinship", occurs when there are fewer births and longer life spans among the family members. Although unexpected, this occurrence engenders - along with a partial overcome of asylum-centred system - a new chance to discuss about mental health within the society, re-discussing the role of the memory and the renewed intergenerational transmissions of knowledge. Since

${ }^{6}$ Even though it has not been drastic, it was noted in some informal interviews made by Filippi (see footnote below). Apparently, the trend for the next years appears to be decreasing rapport professionals/ patients because of underfunding. The region of Veneto is under the national average of Healthcare funding (Toniolo et al. 2010); this fact is particularly relevant for mental health departments because it turned in further cuts to funding, it has been confirmed to Filippi from professionals also in Vicenza area, where in daily outpatient facility (Centro Diurno, CD) there will be one professional to six patients, instead of one to three; furthermore, the provision of homecare assistance on the territory will be limited.

${ }^{7}$ According to Veneto Region Directorate of the Regional Statistical System (2010), the number of people whose age is between 65 and 75 has increased of more than 300,000 units in twenty years, while in the same period the general population rose of 500,000 units only.

${ }^{8}$ See ISTAT data, particularly pp. 3, 8. URL http://www.istat.it/it/files/2017/03/ Statistica-report-Indicatori-demografici 2016.pdf The case study taken into account is located in Veneto, northeastern Italy. In this region, the resident population of 5 million inhabitants showed a growing trend in average life expectancy in the last thirty years. If compared to 1990, where man's was 73.2 and women's 80.7, 2010's expectancy gained 6 points for men (79.1) and 5 points for woman (85.2), slightly higher than national average. Ageing of population is the main characteristic of Veneto's demography, despite the population has slightly increased thanks to one-fifth newborn from migrated people settled between (Toniolo et al. 2010). the $80 \mathrm{~s}$, when the mental hospitals started to lose down, the families have been obliged to embrace again the "loonies" - among them, the "normal" people - not being anymore taken in charge by psychiatry's traditional means. This contact made the private memory of families more acquainted with mental disease problems, but still private and not opened to public display, at least right after closure of asylums. A new understanding of mental disease could have emerged, starting from people whose age now is about 50 years (who lived the late period of the Psychiatric Reform and the Law 180) ${ }^{9}$ to younger.

The challenge launched to public opinion has begun gradually in early 2000s through associations, volunteers, professionals or nonprofessionals' initiatives that lead society to face mental health issue. A problem previously buried within "total institutions", as Erving Goffman defined the asylums and other facilities imprisoning and constraining the individuals "either when dangerous to themselves or others, or because public scandal and they cannot be watched and healed anywhere but in asylums". ${ }^{10}$ Currently, it seems that Italian society has found quite a few means to deal with mentally ill people: e.g., there are many programs to introduce again the suffering people to new professions and to support them through a local social network aware of their problems. At the beginning of twenty-first century at the sunset of mental hospital, something that the oral historian Alessandro Portelli called "collective memory" or "town's memory" is at work yet memory is not a static object observable by scientific means but rather a homeostatic representation changing over the time interacting with socio-historical events (Portelli 2014), inferred by actors' storytelling processes and public narratives. This memory is confronting again the "abnormal people" living in a society that still considers them as "outsider", being accustomed with the idea that "asylums" are "no longer existing". ${ }^{11}$

On the other hand, in Italy these existences routine appear to be forgotten by commoners in their daily routine, left behind in the structures of mental healthcare service. Hence, there may be call a new kind of marginalization, which resembles the one perpetrated through asylum but in a more different, subtle way. Before the Reform Law of Psychiatry was issued in 1978, people branded inconvenient to the eyes of society, or seen as economic burdens by their relatives, used to be locked up in isolated facilities, heavily drugged and kept in bad health and hygienic conditions. This new kind of marginalization is not anymore spatial-based - using physical barriers or places isolated from the urban tissue, even if cities as big as Padua have dozens of mental health facilities in the middle of family houses and near the main roads - instead, it relies on widespread indifference, popular unawareness, psychiatric drugs accepted by now and place for locating people not enough independent to conduct a "normal life" (namely the residential facilities). This impression of unawareness is clearly reflected by a video showed during the "Festival dei Matti" in Venice, made by students mostly into social service who wandered around several cities of northeastern and central Italy asking people what they thought about madness and loonies. The main key question

${ }^{9}$ Accertamenti e trattamenti sanitari volontari e obbligatori, Law n. 180, 13 May 1978. Also known as "Law 180" (Legge 180) or, erroneously, as "Basaglia Law" because of the will of Democratic Psychiatry's chief to improve the patients' conditions.

${ }^{10}$ Disposizioni sui manicomi e sugli alienati (Regulations of Asylums and Alienated), Law no. 36, 14 February 1904.

${ }^{11}$ As children, we clearly remember that many people close to me were afraid of Mental Hospital closure broadcast on news by mass media more than ten years ago. 
was "what do you think about mental illness?", 12 then the huge range of answers heard displays the still-present lack of information about mental health problems among the population in Italy. Also, it affects negatively the activities aimed to prevent the possible chronicity in the national territory, whereby it turns into a lack of agency from the part of non-professionals, such as common citizens interviewed by $\mathrm{Ca}$ ' Foscari students. It is not something as much evident as it was in $60 \mathrm{~s}$, when several Italian photographers depicted people detained behind bars and rods, in a prison-like atmosphere. According to Basaglia, those people were up to "get sick of asylum" or to what have been coldly defined as "institutionalisation phenomena" by Italian laws. ${ }^{13}$ This highlights what Didier Fassin would define "the inequalities of bio politics". It means that "the regulation of the populations through the techniques of knowledge and intervention", ${ }^{4}$ namely the bio politics in foucoultian sense, produces inequalities, as it was, for example, during the racial segregation in South Africa. ${ }^{14}$

The American anthropologist Clifford Geertz claimed that: "The 'control mechanism' view of culture begins with the assumption that human thought is basically both social and public - that its natural habitat is the house yard, the marketplace and the town square. Thinking consists not of "happenings in the head" (though happenings there and elsewhere are necessary for it to occur) but of a traffic in what have been called, by GH Mead and others, significant symbols - words for the most part but also gestures, drawings, musical sounds, mechanical devices like clocks, or natural objects like jewels anything, in fact, that is disengaged from its mere actuality and used to impose meaning upon experience." ${ }^{5}$

In Italy, what Geertz and Mead called "traffic in significant symbols" regarding mental health is still framed mainly by technical (i.e. medical-psychiatrist) and official subjects, notably competence of the Ministry of Health. How many are the nonprofessional people participating in this traffic of symbols in the life out there, busy in the process re-signifying mental health cosmo through their habitués? We asked ourselves what happens when the social thought lingers on an unthinkable world as mental health it is today; after all many people don't even know how close they have been living to the world of mental health services, because its structures and buildings look like normal homes or apartments in an apparently normal associations or networks (Latour 2005). The other way round, this situation recalls the Mackanzie's statement, "Mental health affects one in four of us over a lifetime. That means that everyone knows someone who is affected by mental illness even if we don't realise it". ${ }^{2}$ Before the closure of mental hospitals the people affected by mental illness where confined to buildings hardly distinguishable from prisons, living in a really poor conditions, abandoned by their loved ones and the whole society. The traffic of symbols around mental disease was quite clear embodying the stigma either side of society, the official and the community, though challenged by the movement Psichiatria

${ }^{12}$ The video is the final result of a focus group experience involved in the mental health debate, made by a group of students of Ca' Foscari University of Venice, led by Dr. Anna Poma. The 15-minute footage collects a selection from a sample of 50 interviews; it was showed at the 8th Edition of "Festival dei Matti" hosted in May 2017 in Venice. The festival's goals are to reveal and deconstruct the stereotypical representations made of mentally ill people, also to enhance the rights and role of the citizenship in undoing the residual idea of the more conservative psychiatry to open the society up to a participate process of healthcare. See the webpage http://www.festivaldeimatti.org/presentazione/ ${ }^{13}$ Ministry of Health, Progetto obiettivo tutela salute mentale 1994-1996, published in «Gazzetta Ufficiale», n. 93, 22 April 1994.

${ }^{14}$ The first project of spatial separation in South Africa was introduced in 1900 , during the outbreak of bubonic plague.
Democratica starting from 60 s. However, where are the "significant symbols" which identify the contemporary image of mental healthcare system to nowadays community's eyes? Apparently, watching the video, the need-to-be "achievement-subjects" - following the lead of the "burnout society" characterized by Byung-Chul Han",15 - still weighs on the loonies, whose shoulder we cannot see, either imagine yet because of this new kind of marginalization from daily health issues. After all everybody would say "I caught a cold" as they sneeze, but quite fewer would admit eventually to have a mental disease in front of other people.

The absence of "traffic in significant symbols" obstacles what Marzulli ${ }^{7}$ claims to be indispensable for a successful path of health and social care today: the governance. That is the government processes based on negotiation and integration between social actors to guarantee the efficiency of all the health services. ${ }^{7}$ The role played by the governance is a key point, while in the last years mental illness has been increasing in the world; for instance, depression is considered one of the greatest problems, affecting over 400 million people worldwide. Several theories have been proposed in the attempt of explaining the high prevalence of psychiatric disorders seen today. The Italian psychiatrist Pietro Cipriano ${ }^{8}$ gave a critical interpretation of the phenomena, by analysing different editions of the Diagnostic and Statistical Manual of Mental Disorders (henceforth DSM) edited by the American Psychiatric Association. A turning point of the DSM's third edition (1980) is the lack of psychological theories on mental illness, which makes of it a purely descriptive manual wherein each mental illness has corresponding symptoms. For instance, depression is meant to be associated with the following nine symptoms: "depressed mood appeal or pleasure reduction; loss or gain of weight; loss or gain of appetite; insomnia or hypersomnia, psychomotor agitation or decline, fatigue or energy loss, self-blaming or self-underestimating feelings, decrease of either thinking or focusing ability, suicide or death thoughts". ${ }^{8}$ The third edition of DSM tells us that an individual can be diagnosed with depression if (s) he suffers from a minimum of five symptoms from the afore-mentioned list; furthermore, a person is supposed to suffer sadness for a grief at most one year. Nonetheless, Cipriano $^{8}$ noticed the change of maximal length, reduced to two months by the next edition of the manual (1994) and then to two weeks in the fifth edition (2013). Hence, over two weeks the sadness for a grief turns into depression. This instance makes evident how, still today, the mentally ill individuals are confined to the definition of the disease they are affected by, deprived of their socio-cultural lives and turned into an anomalous state which medical institutions are supposed to heal. The growth of mental illness is also a matter of social signification and representation, "traffic in significant symbols" as quoted by Geertz, on which the psychiatric authority imposes its power. But, quoting again the founder of interpretive anthropology, the mental disease is not just about "happenings in the head", indeed they stem from the socio-cultural context and its hegemonic associations which privilege a particular sort of 'humanity' than other.

Signification and representation processes concern the individual body (by treatment) as well as the socio-political body (by defining

\footnotetext{
${ }^{15}$ In the book The Burnout Society, the philosopher Byung-Chul Han maintains that the contemporary society is no longer analyzable from Michael Foucault's standpoint as a disciplinary society, individuals are not objects of surveillance and punishment places anymore. Rather, from "obligation-subjects" they turned into "achievement-subjects" through the imposition of achievementplaces (bank, office, shopping center, and so on). Apparently, this new type of society is devoted to freedom and rights, instead it is hyperactive, frenetic, enslaved by its own idea of hyper-productivity (Han 2015).
} 
within the social system the priority to cope with, plus the systemical means to pursue it). Concerning the Italian psychiatric revolution, it occurred in the 60s as Franco Basaglia and other Italian psychiatrists' insights expressed the inadequacy of asylums for treating mental-ill patients. ${ }^{9}$ Influenced by American, French and English intellectuals, they were hoping for the opening of asylums that should have been replaced with more appropriate means of cure. Although the most of physician were contrary supporting the marginalization of mentally ill people as best choice for the sake of society, more than one decade after the government declared the closing of mental hospitals in 1978, on the raise of public awareness and grassroots movements. The society as a whole along with the new-born National Health Service in course of shaping were not able to take up the great deal of patients formerly enclosed in asylums and manage their needs.

Now available to all citizens, the psychiatric services have been spread on the urban tissue, relying on the governance and sociocultural agency of social actors. There are cases in which the mentalill individuals are bound to their beds and sedated by a large usage of psychoactive medicines. Thus, in such cases the mental hospital as enclosed structure has become a chemical facility, ${ }^{8}$ in which the individual body even if not socially and spatially marginalized, is controlled through its psychophysiological processes.

\section{Structural and epistemological problems}

The normative regulations for mental health facilities came more than ten years after the mental hospital closing had started. Every region was entrusted to pursue the goals fixed by the national plans for protecting mental health through regional plans fitting properly the human-technological resources and the locations available in each region. The National Health Service (Servizio Sanitario Nazionale, SSN) was created anew in the same year the mental hospitals' closure was announced by the government, namely in 1978. In the SSN, each Italian region is responsible for the healthcare that is organized and provided on the regional territory through the Regional Health and Social Care Plan, meant to meet the priorities and requirements laid out in the National Health Plan and the agreements reached at the State-Regions Conference.

These political choices resulted in the rise of differences in healthcare service development among the regions. Obviously, mental health is included among the goals. A key role is played by the concept of "inter-departmentality" introduced already in 1994 in the National Plan of Mental Health Protection, ${ }^{16}$ that is, the development of communication and collaboration between different medical sectors to increase the effectiveness of psychiatric assistance. An example could be the 90s' drugs abuse that required a coordinate response from physicians and psychiatrists. Consequently, every region adopted a particular approach to mental health chronicity ${ }^{10}$ and other issues regarding childhood and elder age, or more recent ones such as the one posed by immigrants (see for example culture-bound syndrome) from North Africa and Middle-east. ${ }^{11,17}$ This tendency

\footnotetext{
${ }^{16}$ Ministry of Health, Progetto obiettivo tutela salute mentale 1994-1996, published in «Gazzetta Ufficiale», n. 93, 22 April 1994.

${ }^{17}$ "Following approval of the Region's new project on the protection of the population's mental health for the period 2010 - 2012 (Regional Giunta Decree 651, 2010), there will be new measures to address syndromes related to nutritional behaviour, problems affecting teenagers, early psychosis, psychological problems affecting the elderly, psychological problems connected to substance abuse and problems linked to immigration" (Toniolo et al. 2010, p. 114).
}

was intensified by the aforementioned ten-year gap of regulations: the "Law 180" issued the closure of asylums through the creation of territorial services, but "without the necessary implements to realize it", ${ }^{12,18}$ leaving the mental health apparatus only with a dark heritage and just a handful of facilities barely prepared to host patients from ex-mental hospitals.

Now, in 2017, even though some steps have been taken in every region, we cannot talk of a "national mental healthcare system" evenly provided in the whole peninsula, but rather of fragmented practices spread on national territory. Therefore, each region, if no each ULSS, ${ }^{19}$ demands a particular anthropological look to its issues, each one of that relies on the different relationship between the department of mental health and the local actors (hospital, municipality, associations, cooperatives, university and residents) cultivated in the last 40 years.

\section{Looking at mental health of a town}

We will focus on a case study in north eastern Italy, in one of the sanitary districts of Padua city ${ }^{20}$ to trace the contemporary differences of approach to people affected by mental illness from the past. As Toniolo ${ }^{11}$ reported, by 2010 in Veneto there were 348 psychiatric facilities of which $71 \%$ are within ULSSs. While the provision of outpatient facilities is almost entirely public, the private sector mainly manages residential and semi-residential facilities $(37 \%$ and $31 \%$, respectively). There are 3,202 places within the region, equally distributed between residential and semi-residential facilities. According to data since 2009, the Region cared for almost 70,000 psychiatric patients, which represents 17.2 people per 1000 adult inhabitants. In the Veneto, mental health problems occurred slightly more often in women (58\%) than in men; $83 \%$ of psychiatric patients received care in the region's psychiatric facilities while $17 \%$ were treated in hospitals (Service of Psychiatric Care, SPDC). Those treated in designated psychiatric facilities totalled approximately 64,400 in 2009 . The most frequent conditions treated in these settings were schizophrenia $(23 \%)$, depression $(18 \%)$, nervous syndromes $(18 \%)$ and psychosis $(16 \%)$. In hospitals, there were just less than 12,000 people admitted for mental health problems and the most frequently treated conditions were schizophrenia $(22 \%)$, psychosis $(22 \%)$, dementia (17\%) and personality disorders (12\%). The centres for mental health (Centri di Salute Mentale, CSM), which are present in every ULSS, provide information and support but also carry out patient monitoring visits, particularly for people with personality affective and nervous disorders. Around $8.2 \%$ of care takes place in home settings. In semi-residential facilities, on average 3,500 patients

${ }^{18}$ Unless where specified, the translations are the Authors'.

${ }^{19} \mathrm{Namely}$ the local health and social care units (Unità Socio Sanitaria Locale). "The Veneto Regional Health Service (Sistema Sanitario Regionale, SSR) is a complex mix of 21 public ULSSs, each covering approximately 216,000 inhabitants, as well as two AOs (in Padova and Verona) and a public IRCSS that focuses on oncology research. Together these cover 56 public hospitals. There are also 30 private and accredited hospitals, of which one (San Camillo in Venice) is an IRCSS that focuses on motor, communication and behavioural neurorehabilitation" (Toniolo et al. 2010, p. 11).

${ }^{20}$ Padua municipality has the third largest population in the region (about $209^{\prime} 000$ inhabitants) and is the most populous area in the region. The case study is a currently on-going fieldwork started in June 2016, where Filippi employed the ethnographic means of participant observation and semistructured interviews to the people involved in mental health therapies in a day care facility to which we refer to as "the facility" or "facility". Here we focus on the account of Giorgio's experience as an outsider, which came to knowing the mental health service of Padua year by year, with no clue of what was before. All the quotations from interviews have not been published before. 
per year (5.3\% of mental health services users), majority of treatments were rehabilitative or therapeutic. Finally, in residential facilities in 2009,931 people (1.4\% of all psychiatric services users) were assisted within special (protected) residential facilities, with $60 \%$ staying at least 6 months and $15 \%$ staying one year.

Despite the discontinuity found in Italian mental health scenario and its temporary lack of public funding, it is important to understand what kind of associations this "hidden world", better to say "un-seen", is stimulating in order to come up to the public sphere in the plaza, in the market, whereby actors do and undo representations. The role of memory - which interplays with social representations about mentally ill people and psychiatry - has not to be excluded in accounting for the agency of non-professionals and the wider governance definition expressed by Marzulli. ${ }^{7}$ Yet, we know that much work is still to do.

\section{Relations not places}

\section{A case study of multi-participated assistance in padua ${ }^{2}$}

The region of Veneto is divided into 16 local health and social care units (Unità Locali SocioSanitarie, henceforth ULSS) that provide medical care, inside the ULSS is comprised the centre of mental health (Centro di Salute Mentale, henceforth CSM) which organises all the équipe of professionals and manages inpatient and outpatient facilities. It is where the person is supposed to have mental disease and want to receive assistance, or at least is addressed to by the first facility where she/he had their first access. The ULSS of Padua is the 16 and provides healthcare to 900,000 people. Regards of daily-opened outpatient facilities (Centro Diurno, henceforth CD), the province counts 14 structures in the area with a total number of patients as many as 272 in 2010 . This type of structure is meant to provide therapeutic and rehabilitative programs for non-acute cases coming every day from Monday to Friday; it is in charge of some home care services in previously assigned areas too.

The case study observed by Filippi in 2016 was a CD located in the west suburbs of Padua in a quiet residential neighbourhood closed to an urban park partly sided by some small abandoned factories and by a residential complex built anew. The two-store facility followed by the events unfold after the Law 180, initially it hosted a residential community for ex-patients from mental hospital at its upstairs floor. ${ }^{22}$ Then, in 90s, the psychiatrist in charge proposed to use the lower part for supplementary activities for mentally ill people twice a week. Over the years the facility has seen some changes in leading figures, consequently it have had a discontinuous policy about the therapies and rehabilitation activities of facility's users, even if a nurse said that art therapy has lasted in time as a core activity so far. According to the psychologist working there, it was something already experimented in mental hospitals before they were closed and it does not require any huge investment but time. Indeed, she said that activities which help sick people expressing their own selves, such as art, theater and

${ }^{21}$ We thank Dr. Alessandra Capani and all her staff members for their kind collaboration without which we were not able to write a word about this case study. We would like to thank the precious collaboration and patience of Giorgio Gobbo, the musician leading a choir activity in the outpatient facility on which we focus in this section.

${ }^{22}$ These types of facility hosting ex-patients from mental hospitals were called Focolari, literally "hearths" in Italian language. They spread in 80 s in response to the lack of resources in order to find an alternative to mental hospitals which were closing year by year. music, were experimented within the walls of asylums since after the World War II, when many of problems regarded veterans and their war traumas. ${ }^{23}$ Hence, the choice made by the man in charge in early 90 s of employing the facility's empty part for a rehabilitation activity centered on art is not a discontinuity with the past, instead it is a transmission of an habitués already developed informally in some asylums, few well-known examples are provided by Franco Basaglia itself at Gorizia and Trieste's mental hospitals.

The figure currently in charge of the CD observed is a psychologist arrived in 2009. So far she has been leading for the longest period, whereas the facility changed four different leading professionals over the time from 90 s, a clue that exemplifies the temporariness of the situation in ULSS 16 mental health department organization between 90 s and 2000s. The number of users attending therapeutically and rehabilitation activities was around 35 in May 2017, but it changes yearly, as everywhere in the region - because the patient is not forced to undergo therapy. ${ }^{24}$ The therapy and rehabilitation progress of everyone are inspected every 6 months to adapt everyone's iter at the best. Beyond the organizational aspects improved with the steady policy pursued from 2009, there have been several innovations in approaching mental health issue we would like to cite. First, a meeting with all the relatives of facility's users monthly based, this was a twofold way to build a social network against discriminatory and isolating tendency towards the family whose member has mental health problems and to support the general well-being of the whole family. Secondly, some occasions to show the CD's presence and activities outside to the neighbourhood community, such as open day and rally through the town. Thirdly, the weekly activities of filmmaking and music lead by non-professionals, which brought respectively the CD's members to participate to a film festival in Rome and a live concert in the town nearby every year since 2011. Furthermore, some of the users are active (as a group) in posting and sharing on the Facebook page of the facility.

The aforementioned activities are not part any more of the "historical paradigm" of psychiatry, which was more hold on to isolated places where the individual was left without any social and psychological means to find relief in, compelled to cut the outside world off. Though they are not breaking innovations, they embodies a realization of utopian ideals talked by Basaglia through a local network of associations whose characteristics we will explore in the next section. The facility observed has grown in the last twenty years, improving significantly the link with the broader social network in the last 8 years, engaging families and non-professionals for the sake of the individuals affected by mental health problems. Unfortunately, according to CD's personnel more financial cuts are expected to happen in 2018. In the following section we are going to analyse the musical activity carried out in the facility which aims at the full recover of self-expression. It may provide some insights on how the relation between mentally ill people and "outsiders", e.g. non-professionals, put the social memory through a code-switching process challenging the "traditional" representations of loonies.

\footnotetext{
${ }^{23}$ From an interview made by Filippi in May 2017.

${ }^{24} \mathrm{About}$ the compulsoriness there would be a lot to discuss; a professional working in a CD of Vicenza interviewed by Filippi told that usually they watched the patient to take the pharmacological therapy by himself at the facility. Nevertheless, if a patient chose to not come regularly at the facility for therapy or rehabilitation activities, the social network around him could try to find some strategies to push him in complying what suggested by CSM.
} 


\section{Staging the normality}

The music activity featured by facility's users is carried out since 2011 on the psychologist's will. The chain of events and social ties that conducted to officialise this choir as rehabilitation activity was multifaceted; it is well explained through the musician's words during a semi-structured interview accomplished in June 2016 Giorgio. The doctor in charge at the daily centre - where I do my activity - knew my musical band and a nurse working there since long time. Therefore, it was a bet they did. That's they thought they needed somebody for doing this job, they made up their mind about playing music, they were looking for someone sensitive to a particular category of person, like people suffering psychic disease. Therefore, they called me in the summer of a year and there has been the UISP intervention ... they had a project there, psychomotricity, somewhat gymnastic. Then, inside a session of psychomotricity, they set a couple of meetings with me. Then, I have gone there with my guitar and sang all together, De Andre's songs... we chatted and so on. I told the patients what I do. They have been so impressed that, you know, the idea of a regular weekly session came out. Early just a few. However, the year after, more and then even more than before (...) Always I get support from UISP for bureaucracy... it is not easy. I mean, the ULSS has conventions with external institutions, which do activities inside the hospital or structures bounded to it, so it is - through them, I do all the paper, I go there and... How can I say it, their expectations of finding someone able to do this thing have met my pleasure to do it.

The subjects involved are (in order of appearance): he himself, the person in charge, a nurse, the musical band, the UISP, the patients and ULSS. This means that a social network around mental health facilities does exist; consequently, we are talking about relations not just places. After all, the urgency to frame the (underfunded) mental health service into the interconnected social-psychological world of the mentally ill people was defined by the Plan for Protection of Mental Health 2010-2012.25 The region stressed the need for an "informal network" characterized by "a whole set of relations (...) revolving and intertwining around the (facility) users", those are the relations of kinship, relativeness, friendship, neighbourhood, self-reciprocal help. In order to do this, the Plan aims to the integration of the formal answers already tested, with "much flexible means embedded in people's daily life, characterized through the participated definition of needs, the self-production and self-control" (attachment A, p. 2).

Forty years ago the Law 180 started the abolition of the main responsible of social and symbolic marginalization of people affected by mental disease, the asylum, whereas the society had not overcome its prejudices, still existent today as a social stigma looming over the mentally ill person despite a quite huge leap accomplished by healthcare institutions in approaching different problems. Hence, as we said, the prejudice and awareness along with structural inadequacy of the other health services in substituting mental hospitals made the "psychiatric revolution" a very long way to be realised. Nowadays, the underfunding of the departments of mental health along with burnout society's citizens afraid of the foreigners incoming and the "lazy" people - as the psychologist in charge told Filippi, the mentally ill people mostly are pointed at as lazy or no willing to earn their keep, a prejudice shared also for immigrants as Galeazzi ${ }^{13}$ noted in his fieldwork ${ }^{26}$ - don't really leave much room to initiatives promoting mental health.

${ }^{25}$ Regional Giunta Decree, no. 651, 9 March 2010.

${ }^{26}$ The psychologist in charge expressed her vivid concern for those people close to mentally ill subjects thinking about mental disease as a form of laziness. This feature is visible in other representations of socially-stigmatized people, such as beggars and immigrants; it has to be noted that it is part of some rhetoric discourse made everyday by some Italian politicians defined as belonging to right-wing.
Again, it seems the point is a lack of significant symbols in people's habitués, not developed in direct contact with mentally ill individuals or their close relatives. Nonetheless, if compared to the past the present situation is slightly different because of the increased number of non-professionals working in mental health facilities. These actors are somehow on the edge between a partial out -among the "normal" and unaware people and an in -working with psychiatrists, psychologists, nurses and educators, not last with the mental diseased subjects - if still we want to draw a clear line between healthy people and sick people, they frequent either world. The reason why these "outsiders" 27 came in the department of mental health's structures may be an interesting story that shows how the borders between "reason" and "madness" are blurred, while from outside it appears still possible to keep them divided.

Among them, there is Giorgio, the musician leading the music and choir activity at the facility observed so far. Born in Padua in May 1975, he moved in his childhood to a town nearby in the countryside (now a Padua's suburb); here he grew up until his subscription to University of Padua's Course of Literature, engaged not without struggle because his former instruction mostly technical. Eventually he gave it up and chose one year of social service in a residential facility close to the city. This experience and then an afterwards course funded by European Union grounded him in social works as educator, job he had been employed in for almost ten year by a private school.

Once he left the job to embrace fully the music career, in 2011 he has begun collaboration with the second Psychiatric Service of Padua, working in the daily-open facility few hours a week for six months every year. Goal of the activity is the rehabilitation of mental affected people helping them to retrieve communication and expression skills by themselves, thus they can re-enter the society. Giorgio is not an operator and by his words "nor a music-therapist", rather he works there as musician leading the choir of the facility. The feasibility of this kind of activity within the contemporary scenario is not an exception, on the contrary it was planned to be a suitable means to recover people's mental wellness in the Plan for Protection of Mental Health 1996-1998 and the one 1998-2000 in Veneto. As told above, these laws put at the stake the lack of dispositions regarding mental illness after the choice to close mental hospitals in 1978. It was established a therapeutic itinerary with the aims of knowledge and skill empowerment, continuity and coordination of service widespread in every city, trying to cover a large range of age's problematic. In doing this, the citizens and private subjects had a key role in being aware about a new conception of mental health and mental health services, no more something supposed to keep the society away from sicken individuals but rather a way to cope with them from the inside the society without recreating the asylum alienating environment.

The manifold social context no more isolated of mental health facilities is enriched by the positionality of its actors. Besides the in/ out positions he has, in the broader sense Giorgio's role is dual. Inside the ULSS 16, he is an actor-worker, a non-professional chosen for his experience as social educator, but at the same time for his skill in playing guitar, too. The latter is what makes him a professional musician in the society (outside the facility), a role of actor-agent capable of interacting with wider associations of actors. In this sense, he can put in communication the representations performed continuously by the social memory with the more intimate experience in mental health service. Every year he exhibits a live concert ${ }^{27}$ In 2010, there were 3275 personnel working in the Veneto Region's 21 mental health departments (now 16), of which 75\% were direct employees of the ULSSs. In addition, there were 451 mental health professionals working in the Region's five private accredited psychiatric clinics" (Toniolo et al. 2010, p. 114) Giorgio probably counts as an external worker, being employed not directly by ULSS. 
altogether with the people who attended the choir activity during that year so as to bring outside the people involved in mental health services, staging the "normality" in a 50-minute concert in front of a crowded auditorium. According to Margaret Lock and Nancy Scheper-Hughes, ${ }^{14}$ these singing bodies can be read on three levels:

1. The expression of individual's potential and of care for their own wellness

2. The social commitment of all the participants to work for strengthen the social ties

3. A political claim made by mental health department, that aims at a re-appropriation of public space as room for talking about individual's right of well-being without being stigmatized so as to re-negotiate the signification process of minorities.

One more concern is about positionality of Giorgio itself during the choir sessions, whereby he needs no negotiate his role (musician, educator, healthy person) and the related values (poetic, teaching, mental healthiness, health) when he comes in contact with the Otherness of patients. In the interviews Giorgio referred to an activity where 'I' and 'they' were distinctively used to create a distance between his position as skilful musician and their position as beginners, his position as "normal" person and their position as people harmed by life occurrences.

Nicolò, the first time, when the first cycle went on after the early two meetings, how was it? I wonder it was a new experience for you, the first in which you combined music and a profession, a social experience you did already.

Giorgio, How it was? It was... I started, how I could tell you... The thought I have had when I started to work this thing up, it was - at the first - I was very aware to deal with utterly fragile people. Therefore, I had to act with a lot of attention to what was happening, sometimes a song can arouse emotions, touching very delicate strings that is better not to... and then at the same time, I tried to look inside me to find believe that the difference between me, normal and the users attending to this activity, each carrying their own problems, almost not existed. That's like I put myself in between taking in account their fragility and, at the same time, considering them as people being same as me, because the difference was only due to life chances... I mean, it would have been me on the other side as well, I always thought that. So to avoid showing an idea of me like the one singing, doing great live concerts, teaching things.

The interesting fact comes as he use 'we' while narrating an episode of sorrow for the unexpected death of one of the patient singing in the choir. The inclusive reference occurred only in this part of his story telling, then no more, it let think about his endless negotiation of his own role during the activity carried out in the facility. Giorgio's case is a clear example of how the positionality and the social network fundamental for the therapeutic iter are susceptible of a continuous negotiation about the phenomenological and the representational dimensions of the encounter with people affected by psychic disorders. Moreover, being over the in/out makes him an individual able to foster the "traffic of significant symbols" in the wider socio-cultural scenario.

\section{Conclusion}

The Mental Health Laws, along with Health Reforms, contributed to realize the cultural change, which intellectuals hoped for in $60 \mathrm{~s}$ and 70s, freedom of choice on healthcare, community services and closure of mental hospitals. In 1994, the first law changed effectively the scattered and confused situation caused by the lack of preparation to solve the aftermath of asylums' closure. What the asylum was, the systemic response to social deviance from a productive regime supposed to be the norm, left a problematic emptiness at the closing. The "lunatics" had been to taken up by families or unsuitable hospital facilities, both without the resources or competences to treat mental illness but with psychoactive medicines. The law, from its basic regulations supposed to be extended to every region enacted in 1994, progressively defined a circuit of interdisciplinary facilities and human resources, in order to manage continuously the demand for psychiatric help within the society of twenty-first century. To us it seems that, beyond the important steps moved through the Veneto's Regional Plan for Mental Healthcare, published in 2010, by the acknowledgement of the manifold role of social ties such as family, friends, neighbourhood for the individuals' mental health well-being, differences between mental health departments (composition, general organization, activities, patient's iter) - not limited to be only between two regions but extended even within the same region - are still rowing against a process of de-institutionalization evenly pursued in the whole country. Furthermore, a common approach on mental health issues has not be reached yet, conversely some chronicity appear to be still at stake, enforced by new ones, such as increasing in youth unemployment and presence of immigrants from African states who got through traumatic experiences and strive to be socialized in Italian society. ${ }^{28}$ All these points call for an even more opened mental health assistance in the disciplinary sense of term. Cultural, social and psychological sphere of the individuals cannot be treated as separated and non-communicable any longer. Thus, also cultural and social anthropology is needed on the field to build a complete concept of "health", without "mental" being apart or between brackets, so as to attempt to enact what has been discussed twelve years ago in Helsinki by WHO in the European Ministerial Conference on Mental Health. ${ }^{29}$

The instance of Giorgio's musical activity at the facility - one among many in Italy - calls out for further attention to a feature based on social interdependence: sensitivity. This infers the individual action as well as the group, therefore it belongs to the social sphere questioned by social sciences. In Giorgio's case the song language (as means, but also as object of discussion) is the main medium for negotiating and questioning the status of individuals during the choir session. In Padua's department of mental health psychoactive medicines are also used, but at least part of the city psychiatric assistance relies more on social ties and people's awareness, as showed recently by several initiatives involving participation of formal institutions and of citizens, too. ${ }^{30}$ The musical workshop held

${ }^{28}$ Recently, the government elaborated a National Plan of "Spread Hospitality" (Programma di Accoglienza Diffusa) to house the people settling off from North Africa to Italy, a number that rapidly increased in the last years with overwhelming consequences for the immigrant's centers. This constitutes relatively a new issue for departments of mental health (see Ministero della Salute 2008), which have to face a totally new set of problems bound to forced migrations. Therefore, "traditional" mental healthcare's competence and issues usually handled by ethno psychiatry overlap, requiring more interdisciplinary collaboration, as highlighted by Didier Fassin. ${ }^{15,16}$

${ }^{29}$ One of the more representative declarations was "We endorse the statement that there is no health without mental health". ${ }^{17}$

${ }^{30}$ We refer to DiversaMente, which means both "different mind" and "differently", one day dedicated to mental health in Padua and towns nearby that is followed by many other side-events organised during all time of the year. 
by Giorgio ends every year with a public live concert, which runs against the idea of asylum as mandatory location for keeping society safe from mentally ill people. Here the mental disease is not staged as a depiction of weirdness, instead it vanishes among the singers, both professionals and patients On the other way round, the performance is permitted by reinforcing the collaboration between different social actors, included musician and "lunatics", those who could look improper to a frenetically productive burnout society. That may be a motivation to adopt a more sensitive and integrated approach to mental illness in other departments and regions, to overcome the dark heritage of mental hospitals: the chemical asylum cited by Cipriano ${ }^{8}$ which still overruns the bodies of whom cannot control by imposing the social norm. Eventually, according to Nietzsche, a life without music should be a mistake. ${ }^{18,19}$

\section{Acknowledgements}

None.

\section{Conflict of interest}

Author declares there is no conflict of interest in publishing the article.

\section{References}

1. Valeria BP, Liberi tutti. Manicomi e psichiatri in Italia: una storia del Novecento. Il Mulino, USA; 2009. p. 364.

2. Jessica M. Prioritising mental health. UNA-UK, UK; 2016.

3. Donfut AC, Segalen M. Il secolo dei nonni. La rivalutazione di un ruolo. In: Armando, editor. Le siècle des grands-parents. Paris, France; 2005.

4. Fassin D. Ripoliticizzare il mondo: studi antropologici sulla vita, il corpo e la morale. Ombre corte. Italy; 2014.

5. Geertz C. The Impact of the Concept of Culture on the Concept of Man The Interpretation of Cultures. Basic Books, USA; 1973.
6. Chul HB. The burnout society. Stanford, USA; 2015.

7. Marzulli, Michele. Elementi di complessità e criticità della governance regionale. In: Bertin $\mathrm{G}$, Cipolla $\mathrm{C}$, editors. Verso differenti sistemi sanitari regionali. Edizioni Ca'Foscari, Italy; 2013. p. 52-77.

8. Cipriano P. Il manicomio chimico, La società dei devianti. Elèuthera. Italy; 2015,2016.

9. Foot J. La Repubblica dei matti. Franco Basaglia e la psichiatria radicale in Italia, 1961-1978, Feltrinelli. Italy; 2014.

10. Ministero della Salute. Linee di indirizzo nazionali per la salute mentale. Rome; 2008. p. 1-34.

11. Toniolo F, Mantoan D, Maresso A. Veneto Region, Italy Health System Review. Health Syst Transit. 2012;14(1):1-138.

12. Basaglia OF. Nota introduttiva alla nuova edizione. L'istituzione negata, Baldini \& Castoldi, Italy; 1998.

13. Galeazzi S. Migranti, biopolitiche e sanità. Pratiche d'accesso all'assistenza sanitaria in Italia. Rivista Italiana di Antropologia Applicata. 2016b;2-2:40-52.

14. Lock M, Hughes SN. Medical Anthropology, Contemporary Theory and Method. In: Johnson T, Sargent C, editors. A critical-interpretative approach in medical anthropology: rituals and routines of discipline and dissent. Praeger Publishers, USA; 1990. p. 47-72.

15. Fassin D. L'ethnopsychiatrie et ses résaux. L'influence qui grandit in Genèses. 1999;35(1):146-171.

16. Fassin D. Les politiques de l'ethnopsychiatrie. La psyche africaine, des colonies africaines aux banlieues parisiennes in L'Homme. 2000;153:231-250.

17. WHO. Mental Health Declaration for Europe, Facing the Challenges, Building Solutions. World Health Organization Finland. 2005. p. 1-6.

18. Emilio L, Fede DS, Centottanta. Riflessione collettiva sulla Legge di Riforma della Psichiatria. Psichiatria Democratica, Italy; 2008.

19. Giovanni P. Antropologia medica. Carocci, Italy; 2005. 